\title{
UTILISATION OF INFRARED STABILISED IMMATURE RICE GRAINS IN A CEREAL BASED FERMENTED FOOD: TARHANA
}

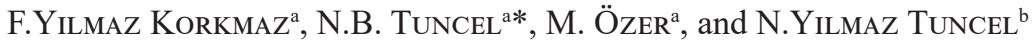 \\ ${ }^{a}$ Department of Food Engineering, Faculty of Engineering, Onsekiz Mart University, 17100, Çanakkale. Turkey \\ ${ }^{\mathrm{b}}$ Department of Food Technology, Çanakkale School of Applied Sciences, Onsekiz Mart University, 17100, \\ Çanakkale. Turkey
}

(Received: 7 November 2019; accepted: 6 February 2020)

\begin{abstract}
Immature rice grain is one of the under-valued by-products of rice milling industry. In this study, it was aimed to investigate the effects of immature rice grain flour (IRGF) substitution to tarhana, which is a traditional cereal-based, fermented food product. IRGF was replaced by refined wheat flour at the levels of 0 (control), 30, 50, 70, and 100\%, and the effect of this replacement on the contents of crude fat, ash, protein, dietary fibre, phytic acid, minerals, vitamins $\mathrm{B}_{1}$ and $\mathrm{B}_{2}$, tocopherols, $\gamma$-oryzanol contents and sensory properties were investigated. It was shown that stabilised IRGF remarkably improved nutritional properties of the end product without adversely affecting sensory quality up to $50 \%$. In conclusion, it could be suggested that stabilised IRGF has a promising potential for many food applications due to being cheap, accessible, nutritious, and gluten-free.
\end{abstract}

Keywords: immature rice, tarhana, stabilisation, infrared, $\gamma$-oryzanol, insoluble dietary fibre

Tarhana is a traditional cereal-based, fermented food product consumed in Turkey. It is typically prepared by mixing yogurt, wheat flour, yeast, and a variety of vegetables and spices (onions, tomatoes, paprika, salt, mint, thyme, etc.). The dough is then fermented, dried, and granulated. Since it has a low moisture content (around 10\%) and low $\mathrm{pH}$ (due to the acids produced by lactic acid bacteria and yeasts) tarhana can be stored for 2-3 years (ERKAN et al., 2006). It can be readily reconstituted for soup making. The ingredients used for tarhana preparation can vary from region to region, however, cereals and yogurt are the main components (DAĞLIOĞLU, 2000).

Immature rice grain is one of the by-products of rice milling process. Immature rice grains are whole grains such as brown rice, albeit having green-yellow seed coat and / or being chalky and brittle. Immature rice grains are always present to some extent depending on mostly environmental conditions, since each rice grain in the field cannot be at the same maturity level during harvest (BUGGENHOUT et al., 2013). Broadly speaking, approximately $5 \%$ of immature rice is obtained during milling. It was reported that immature rice grains contained higher levels of protein, reducing sugar, vitamin $C, B_{2}, B_{3}, B_{6}, \beta$-carotene, total phenolics, total flavonoids, dietary fibre, tocopherols, and tocotrienols than mature grains (LIN \& LAI, 2011; JI et al., 2013). Although they have a notable potential for use in functional foods and nutraceuticals, they are mainly utilised as feed due to being susceptible to rancidity. It was found that free fatty acid content, which is the primary measure of rancidity, of immature rice grain increased from $5.49 \%$ to $35.71 \%$ in 3 months of storage at room temperature (YILMAZ et. al., 2018). Therefore, an effective stabilisation process needs to be employed in order to utilise immature rice grains as food rather than feed.

\footnotetext{
* To whom correspondence should be addressed.

Phone: +902862180018/1903; fax: +902862180541; e-mail:baristuncel@comu.edu.tr
}

0139-3006 (C) 2020 The Author(s) 
The objective of this study was to investigate the physicochemical, nutritional, functional, and sensorial properties of tarhana made with refined wheat flour partially or completely replaced by immature rice gran flour.

\section{Materials and methods}

\subsection{Materials}

Immature rice grains (variety of Osmac1k-97), which were separated from their mature counterparts by an industrial-scale thickness grader, were obtained from a rice milling plant in Çanakkale, Turkey (Özer Ticaret Ltd. Şti) immediately after milling. Remained impurities such as foreign matters and broken grains were also separated using a laboratory-scale trieur (CRM-1252T, Yaşar Makina, Samsun, Turkey) after their arrival to the laboratory. The cleaned immature rice grains were soaked in water for $10 \mathrm{~min}$, were allowed to drain for 5 min, and were stabilised using a laboratory type infrared (IR) stabilisation system, which was described in detail in previous studies (YILMAZ et al., 2014a, b). Stabilisation was carried out at $1600 \mathrm{~W}$ for 4 min using medium-wave IR emitters (Heraeus Noblelight, Hanau, Germany) based on the outcomes of a previous study (YILMAZ et al., 2018). IR stabilised immature grains were milled through a roller mill (Prodigy 4000, Bastak Inc., Ankara, Turkey) and sieved through $500 \mu \mathrm{m}$ particle size sieves (Retsch AS200, Haan, Germany) to obtain IR stabilised immature rice grain flour (IRGF). Other ingredients used for the preparation of tarhana were purchased from the local markets.

\subsection{Preparation of tarhana}

To prepare tarhana samples, $250 \mathrm{~g}$ of tomato $(16 \%), 250 \mathrm{~g}$ of paprika (16\%), $125 \mathrm{~g}$ of onion $(8 \%), 300 \mathrm{~g}$ of yogurt $(20 \%), 75 \mathrm{~g}$ of salt $(5 \%), 5 \mathrm{~g}$ of instant yeast $(0.33 \%)$, and $1500 \mathrm{~g}$ of refined wheat flour or IRGF were used. IRGF was replaced with refined wheat flour at the levels of $30,50,70$, and $100 \%$ (w/w), whereas control tarhana sample did not contain IRGF $(0 \%)$. To prepare tarhana samples under laboratory conditions; onion, tomato, and paprika were chopped in a food processor (Arzum, AR-132, Turkey) and blended. Then, all other ingredients (except for the flour or IRGF) were added and mixed until complete homogenisation. After the addition of refined wheat flour or IRGF, the mix was kneaded for $10 \mathrm{~min}$ (Kitchen aid, Michigan, ABD), and the resulting dough samples were taken into covered containers (Jeio Tech, IS-971R, Seoul, Korea) and incubated at $35{ }^{\circ} \mathrm{C}$ for 3 days for fermentation. The fermented dough samples were dried in a convection oven at $55{ }^{\circ} \mathrm{C}$ for about $21 \mathrm{~h}$. After the drying process, tarhana samples were ground into granulated form with a microniser mill (Yuhong, IC-02A, China) and sieved through $300 \mu \mathrm{m}$ particle size sieves. Then, granulated tarhana samples were spread out on trays and allowed to stand at room temperature for about 3 days. Tarhana samples were stored in aluminium packed zip-loc bags. Tarhana production was repeated twice.

\subsection{Proximate analyses}

Moisture, crude fat, crude protein $(\mathrm{N} \times 5.7)$, and ash contents of the samples were measured according to the standard methods of AACC (AACC, 2000). Soluble, insoluble, and total dietary fibre contents of the samples were measured using Megazyme enzyme kits 
(Megazyme, Wicklow, Ireland) according to the referenced procedure (AACC Method No: 32-07) (AACC, 2000). Phytic acid content of the tarhana samples was determined according to the spectrophotometric AOAC method (Method No: 986.11) (AOAC, 2000).

\subsection{Minerals}

Mineral composition of tarhana samples was measured according to the method outlined by ÖZER and co-workers (2018). The results were expressed as $\mathrm{mg} \mathrm{kg}^{-1}$.

\subsection{Vitamins and $\gamma$-oryzanol}

Thiamine $\left(\mathrm{B}_{1}\right)$ and riboflavin $\left(\mathrm{B}_{2}\right)$ contents of the tarhana samples were analysed using reverse phase liquid chromatography according to the validated method of YILMAZ (2015). Tocopherols and $\gamma$-oryzanol were determined according to the methods explained in detail in a previous study (YILMAZ et al., 2014a).

\subsection{Sensory analysis}

Consumer acceptance test was used to determine the sensorial properties of tarhana samples according to MEILGAARD and co-workers (1999). Since the tarhana granules are consumed in the form of soup, tarhana soup was prepared to test the sensorial quality by mixing tarhana granules with water $\left(1: 10, \mathrm{~g} \mathrm{ml}^{-1}\right)$ and simmering the mixture over medium heat with constant stirring. Cooking was ended 5 min after boiling. Cooked soup samples were served to the panellists at about $70{ }^{\circ} \mathrm{C}$ in plastic cups, which were numbered with random 3-digit numbers. A 7-point hedonic scale, which ranged from "excellent" (7) anchored on the right and "terrible" (1) anchored on the left was used for evaluation. The panellists were also asked to rank the samples according to their preference based on overall acceptability. Panellists $(n=63)$ were informed about the experiment and the use of hedonic scale before evaluation. A sensory panel informed-consent form was available for the panellists.

\subsection{Statistical analysis}

One-way ANOVA was performed to evaluate the effect of IRGF substitution on the noted properties using MINITAB (ver. 17, StatSoft, Inc., OK, USA). Tukey's test was used for multiple comparisons at a significance level of 0.05 . Solely, the results of the sensorial analyses were evaluated with Kruskal-Wallis test due to being categorical data. Dunn test was used to differentiate between the mean sensory scores. All results were expressed as mean \pm standard error.

\section{Results and discussion}

\subsection{Proximate composition}

Moisture contents of the tarhana samples ranged between $4.77 \%$ and $6.26 \%$. Crude fat content of the samples showed a gradual increase with increasing IRGF substitution level $(\mathrm{P}<0.05)$. It is an expected result, since crude fat content of IRGF $(4.85 \%)$ was notably higher than refined wheat flour. Although crude protein content of control tarhana was slightly higher $(\mathrm{P}<0.05)$ than its counterparts substituted with IRGF, the variation was lower than $1 \%$, 
which is not practically significant. Incorporation of IRGF significantly increased the ash content of tarhana $(\mathrm{P}<0.05)$. Insoluble dietary fibre content showed a gradual and remarkable increase with IRGF substitution $(\mathrm{P}<0.05)$. Replacement of refined wheat flour by IRGF resulted an increase from $0.59 \%$ to $7.48 \%$ in insoluble dietary fibre content of tarhana. However, soluble dietary fibre content of the samples was not significantly affected by IRGF substitution $(\mathrm{P}>0.05)$. Phytic acid content of the tarhana samples significantly increased with increasing IRGF substitution level $(\mathrm{P}<0.05)$ (Table 1). Phytic acid is considered as an antinutrient, primarily due to its ability to bind divalent cations, causing a decrease of their bioavailability. On the other hand, it is receiving increasing attention owing to its anti-cancer and cholesterol lowering effects (URBANO et al., 2000).

Table 1. Proximate composition of the tarhana samples

\begin{tabular}{lccccc}
\hline & & \multicolumn{3}{c}{ Substitution level (\%) } \\
& 0 (control) & 30 & 50 & 70 & 100 \\
\hline Moisture (\%) & $6.26 \pm 0.24$ & $4.96 \pm 0.35$ & $4.77 \pm 0.34$ & $5.42 \pm 0.50$ & $5.13 \pm 0.37$ \\
Crude fat (\%, d.w.) & $1.58 \pm 0.07^{\mathrm{D}}$ & $2.54 \pm 0.09^{\mathrm{C}}$ & $3.32 \pm 0.09^{\mathrm{B}}$ & $3.58 \pm 0.08^{\mathrm{B}}$ & $4.64 \pm 0.14^{\mathrm{A}}$ \\
Crude protein (\%, d.w.) & $11.93 \pm 0.02^{\mathrm{A}}$ & $11.80 \pm 0.04^{\mathrm{AB}}$ & $11.76 \pm 0.09^{\mathrm{AB}}$ & $11.81 \pm 0.31^{\mathrm{AB}}$ & $10.98 \pm 0.01^{\mathrm{B}}$ \\
Ash (\%, d.w.) & $4.70 \pm 0.07^{\mathrm{B}}$ & $5.64 \pm 0.52^{\mathrm{AB}}$ & $6.03 \pm 0.18^{\mathrm{AB}}$ & $6.30 \pm 0.13^{\mathrm{A}}$ & $6.07 \pm 0.18^{\mathrm{AB}}$ \\
Soluble dietary fibre (\%) & $3.01 \pm 0.41^{\circ}$ & $3.32 \pm 0.22^{\circ}$ & $2.93 \pm 0.22$ & $2.79 \pm 0.29$ & $2.65 \pm 0.25$ \\
Insoluble dietary fibre (\%) & $0.59 \pm 0.26^{\mathrm{D}}$ & $2.42 \pm 0.18^{\mathrm{C}}$ & $4.11 \pm 0.26^{\mathrm{BC}}$ & $5.18 \pm 0.53^{\mathrm{B}}$ & $7.48 \pm 0.23^{\mathrm{A}}$ \\
Total dietary fibre (\%) & $3.59 \pm 0.15^{\mathrm{D}}$ & $5.74 \pm 0.40^{\mathrm{C}}$ & $7.04 \pm 0.04^{\mathrm{BC}}$ & $7.98 \pm 0.24^{\mathrm{B}}$ & $10.13 \pm 0.48^{\mathrm{A}}$ \\
Phytic acid (mg g ${ }^{-1}$ ) & $0.14 \pm 0.04^{\mathrm{D}}$ & $0.55 \pm 0.10^{\mathrm{CD}}$ & $0.71 \pm 0.05^{\mathrm{C}}$ & $1.47 \pm 0.05^{\mathrm{B}}$ & $2.50 \pm 0.14^{\mathrm{A}}$ \\
\hline
\end{tabular}

Means within each row followed by different capital letters are statistically different $(\mathrm{P}<0.05)$.

\subsection{Minerals}

No significant change was observed in $\mathrm{Na}, \mathrm{Ca}$, and $\mathrm{Fe}$ contents of the tarhana samples with the substitution of IRGF ( $\mathrm{P}>0.05)$. On the other hand, $\mathrm{Mg}, \mathrm{K}, \mathrm{P}$, and $\mathrm{Zn}$ contents of the samples significantly increased in varying proportions $(\mathrm{P}<0.05)$ (Table 2$)$. The highest relative increase was observed in $\mathrm{Mg}$ content. $\mathrm{Mg}$ content of the tarhana samples made of IRGF $(100 \%)$ was about 6 -fold higher than that of samples made of refined wheat flour (control). Besides, K, P, and Zn contents of the tarhana samples increased $54 \%, 146 \%$, and $187 \%$, respectively, with the replacement of refined wheat flour by IRGF at the level of $100 \%$. Mineral contents of two different rice cultivars during grain development were studied by Ji and co-workers (2013). The authors found significantly higher amounts of $\mathrm{K}$ and $\mathrm{Ca}$ in immature grains compared to mature grains for both rice cultivars. The mineral composition is affected by many genetic and environmental factors, and therefore it is not always possible to generalise the results. However, it was observed that IRGF substitution clearly increased the mineral content of tarhana. 


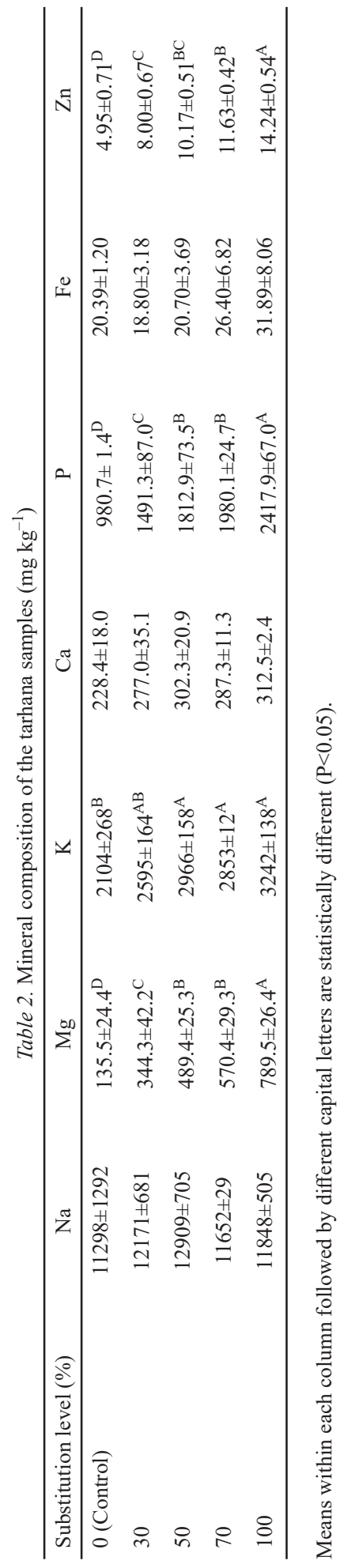

Acta Alimentaria 49, 2020 


\subsection{Vitamins}

Thiamine and riboflavin contents of the tarhana samples ranged between $1.15-1.46 \mathrm{mg} \mathrm{kg}^{-1}$ and $2.78-3.05 \mathrm{mg} \mathrm{kg}^{-1}$, respectively. In many studies, the concentration of thiamine was found to be higher than riboflavin in either tarhana (IBANOĞLU et al., 1997; EKINCI, 2005) or rice bran / brown rice (LeBIEDZINSKA \& SZEFER, 2006; YILMAZ \& TUNCEL, 2015). In a previous study, raw rice bran was analysed using the same analytical methodology, and it was found that thiamine and riboflavin contents were $3.69 \mathrm{mg} \mathrm{kg}^{-1}$ and $0.09 \mathrm{mg} \mathrm{kg}^{-1}$, respectively (Yilmaz \& TUNCEL, 2015). Low thiamine results may be attributed to susceptibility of thiamine to heat. IBANOĞLU and co-workers (1997) found $1.5-2.2 \mathrm{mg} \mathrm{kg}^{-1}$ thiamine and $0.7-$ $0.9 \mathrm{mg} \mathrm{kg}^{-1}$ riboflavin in tarhana and reported that oven-drying at $55^{\circ} \mathrm{C}$ for $48 \mathrm{~h}$ caused about $30 \%$ of thiamine loss, while the riboflavin contents of the samples did not change significantly. Similarly, we have found that IR stabilisation resulted in a significant decrease (up to $42 \%$ ) in thiamine content of rice bran, while its effect on riboflavin content was statistically insignificant. Furthermore, JI and co-workers (2013) reported that riboflavin content of immature rice was dramatically higher than that of mature rice. The authors studied two different rice cultivars and found that riboflavin contents of the samples decreased from 87.99 $\mu \mathrm{g} / 100 \mathrm{~g}$ to $2.16 \mu \mathrm{g} / 100 \mathrm{~g}$ and from $97.45 \mu \mathrm{g} / 100 \mathrm{~g}$ to $8.24 \mu \mathrm{g} / 100 \mathrm{~g}$ during rice grain development (from $15^{\text {th }}$ to $40^{\text {th }}$ day after heading). These results may explain higher riboflavin levels of immature rice grain compared to thiamine. Besides, it was also observed that thiamine and riboflavin contents of the tarhana samples were not significantly affected by IRGF substitution $(\mathrm{P}>0.05)$.

Among tocopherol homologs, solely $\alpha$-tocopherol could be quantified in tarhana samples. Although $\beta$ - and $\gamma$-tocopherols were also detected in the samples, their amounts were under the limit of quantification (LOQ). In addition, $\delta$-tocopherol could not be detected. Almost 3-fold higher $\alpha$-tocopherol was found in tarhana made of IRGF $(100 \%)$ when compared to control (Table 3).

\begin{tabular}{lcccc}
\multicolumn{4}{c}{ Table 3. Thiamine $\left(\mathrm{B}_{1}\right)$, riboflavin $\left(\mathrm{B}_{2}\right)$, tocopherol and $\gamma$-oryzanol contents of the tarhana samples $\left(\mathrm{mg} \mathrm{kg}^{-1}\right)$} \\
\hline Substitution level $(\%)$ & $\mathrm{B}_{1}$ & $\mathrm{~B}_{2}$ & $\boldsymbol{\alpha}$-Tocopherol & $\gamma$-Oryzanol \\
\hline 0 (Control) & $1.15 \pm 0.03$ & $3.05 \pm 0.08$ & $11.80 \pm 2.43^{\mathrm{B}}$ & n.d. \\
30 & $1.32 \pm 0.09$ & $2.78 \pm 0.06$ & $12.25 \pm 2.15^{\mathrm{B}}$ & $210.65 \pm 0.51^{\mathrm{D}}$ \\
50 & $1.26 \pm 0.06$ & $2.94 \pm 0.10$ & $18.45 \pm 6.04^{\mathrm{AB}}$ & $325.00 \pm 12.50^{\mathrm{C}}$ \\
70 & $1.14 \pm 0.07$ & $2.95 \pm 0.16$ & $28.02 \pm 0.18^{\mathrm{A}}$ & $417.70 \pm 16.80^{\mathrm{B}}$ \\
100 & $1.46 \pm 0.08$ & $3.00 \pm 0.29$ & $29.54 \pm 0.81^{\mathrm{A}}$ & $684.80 \pm 26.90^{\mathrm{A}}$ \\
\hline
\end{tabular}

Means within each column followed by different capital letters are statistically different $(\mathrm{P}<0.05)$. n.d. means not detected

In a previous study, it was found that $\alpha$-tocopherol contents of unprocessed and infrared stabilised (1600 W, $4 \mathrm{~min}$ ) IRGF were $7.56 \mathrm{mg} \mathrm{kg}^{-1}$ and $6.12 \mathrm{mg} \mathrm{kg}^{-1}$, respectively (YILMAZ et. al., 2018). Other ingredients of the tarhana might also be contributed to $\alpha$-tocopherol content of the end product. O'CALLAGHAN and co-workers (2019) reported that $\alpha$-tocopherol content was significantly higher in tarhana products containing red pepper in comparison with the samples, which did not contain red pepper. The authors also stated that as the fermented milk (yogurt) content of the experimental blends was increased there was a corresponding increase in $\alpha$-tocopherol content of tarhana and kishk products. 
Gamma-oryzanol is mainly composed of esters of trans-ferulic acid with sterols or triterpenic alcohols. The most accessible natural source of $\gamma$-oryzanol is rice bran, however, some components of $\gamma$-oryzanol can also be found in the pericarp of other cereals such as wheat, rye, corn, and triticale (SEITz, 1989). Control tarhana sample, which was made of $100 \%$ refined wheat flour, did not contain $\gamma$-oryzanol as expected. However, $\gamma$-oryzanol content of the tarhana samples increased proportionally and significantly with increasing IRGF substitution level $(\mathrm{P}<0.05)$.

\subsection{Sensory properties}

Results of the consumer acceptance test are shown in Table 4. IRGF substitution significantly affected all sensorial properties $(\mathrm{P}<0.05)$. Generally, replacement of IRGF by wheat flour at the level of $50 \%$ or higher negatively affected sensorial acceptance. Tarhana sample made of $100 \%$ IRGF had the lowest appearance score probably due to the greenish colour. Consistency scores of the tarhana samples substituted with IRGF was lower than that of control. This result may be related to either decreased starch content of IRGF substituted samples or the difference between the properties of wheat and rice starches. Flavour/taste of the tarhana was liked by the panellists up to 70\% IRGF substitution level. However, the panellists gave dramatically lower flavour/taste scores for tarhana samples made of $100 \%$ IRGF. Additionally, the panellists were asked to rank the samples based on overall acceptability. As can be seen from Table 4, the overall acceptability of tarhana decreased over 50\% IRGF substitution level $(\mathrm{P}<0.05)$. However, it can also be seen from the results that substitution of IRGF up to $70 \%$ resulted in acceptable soup properties, when the sensory properties were evaluated individually (Table 4). Sensory quality of the soups can be improved by further studies.

Table 4. Sensory scores of the consumer acceptance test

\begin{tabular}{lcccc}
\hline $\begin{array}{l}\text { Substitution } \\
\text { level }(\%)\end{array}$ & Appearance & Consistency & Flavour/taste & $\begin{array}{c}\text { Overall acceptance } \\
\text { (rank) }\end{array}$ \\
\hline $0($ Control $)$ & $6.60 \pm 0.26^{\mathrm{A}}$ & $6.06 \pm 0.23^{\mathrm{A}}$ & $5.73 \pm 0.28^{\mathrm{A}}$ & $2.44 \pm 0.18^{\mathrm{A}}$ \\
30 & $5.85 \pm 0.20^{\mathrm{AB}}$ & $5.66 \pm 0.23^{\mathrm{AB}}$ & $5.69 \pm 0.27^{\mathrm{A}}$ & $2.60 \pm 0.15^{\mathrm{AB}}$ \\
50 & $6.07 \pm 0.21^{\mathrm{A}}$ & $5.81 \pm 0.23^{\mathrm{A}}$ & $5.63 \pm 0.25^{\mathrm{A}}$ & $2.44 \pm 0.14^{\mathrm{A}}$ \\
70 & $5.76 \pm 0.22^{\mathrm{AB}}$ & $5.30 \pm 0.25^{\mathrm{AB}}$ & $5.14 \pm 0.29^{\mathrm{A}}$ & $3.20 \pm 0.16^{\mathrm{B}}$ \\
100 & $4.98 \pm 0.22^{\mathrm{B}}$ & $4.71 \pm 0.24^{\mathrm{B}}$ & $3.68 \pm 0.27^{\mathrm{B}}$ & $4.30 \pm 0.11^{\mathrm{C}}$ \\
\hline
\end{tabular}

Means within each column followed by different capital letters are statistically different $(\mathrm{P}<0.05)$.

\section{Conclusions}

In conclusion, the use of IRGF instead of refined wheat flour in tarhana formulation provided additional nutritional advantages by raising the levels of minerals, insoluble dietary fibre, and bioactive components such as $\alpha$-tocopherol and $\gamma$-oryzanol without adversely affecting sensory quality up to $50 \%$. Higher IRGF substitution levels may be possible if necessary measures are taken for sensory optimisation. Immature rice grains are one of the by-products of rice milling industry, and therefore procurement of immature rice grains as raw material is easy and cheap. However, it should be emphasized that IRGF should be stabilised before use for food safety reasons. Moreover, due to being gluten-free, IRGF is also a promising 
ingredient for food products produced for celiac patients and people who have gluten intolerance.

This study was funded by the Turkish Scientific and Technological Research Council (TUBITAK) (Project No: 1150605). Fatma Yılmaz Korkmaz and Melike Özer were granted a scholarship for the noted project.

\section{References}

AACC (2000): Approved methods of American Association of Cereal Chemists. American Association of Cereal Chemists, 10th ed. Inc. Minnesota, USA.

AOAC (2000): Official methods of analysis. Association of Official Analytical Chemists, 17th ed., Inc. Maryland, USA.

Buggenhout, J., Briss, K., Celus, I. \& Delcour, J.A. (2013): The breakage susceptibility of raw and parboiled rice: A review. J. Food Eng., 117(3), 304-315.

DAĞLIOĞLU, O. (2000): Tarhana as a traditional Turkish fermented cereal food. Its recipe, production and composition. Nahrung, 44(2), 85-88.

EKINCI, R. (2005): The effect of fermentation and drying on the water-soluble vitamin content of tarhana, a traditional Turkish cereal food. Food Chem., 90(1-2), 127-132.

ERKan, H., Çelik, S., Bilgi, B. \& KöKsel, H. (2006): A new approach for the utiliation of barley in food products: Barley tarhana. Food Chem., 97(1), 12-18.

IbanoĞLu, S., Ainsworth, P. \& Hayes, G.D. (1997): In vitro protein digestibility and content of thiamine and riboflavin in extruded tarhana, a traditional Turkish cereal food. Food Chem., 58(1-2), 141-144.

Ji, C.M., Shin, J.A., Cho, K.W. \& LeE, K.T. (2013): Nutritional evaluation of immature grains in two Korean rice cultivars during maturation. Food Sci. Biotechnol., 22(4), 903-908.

Lebiedzinska, A. \& Szefer, P. (2006): Vitamins B in grain and cereal grain food, soy-products and seeds. Food Chem., 95(1), 116-122.

LIN, P.Y. \& LAI, H.M. (2011): Bioactive compounds in rice during grain development. Food Chem., 127(1), 86-93.

Meilgaard, M., Civille, G.V. \& CARr, B.T. (1999): Sensory evaluation techniques; CRC Press, Boca Raton. pp. 255-309.

O’Callaghan, Y.C., Shevade, A.V., Guinee, T.P., O’Connor, T.P. \& O’Brien, N.M. (2019): Comparison of the nutritional composition of experimental fermented milk: Wheat bulgur blends and commercially available kishk and tarhana products. Food Chem., 278, 110-118.

Özer, M., Yilmaz Tuncel, N. \& Tuncel, N.B. (2018): The effects of infrared stabilized immature rice grain flour in gluten-free bread preparation. Cereal Chem., 95, 527-535.

SEITZ, L.M. (1989): Stanol and sterol esters of ferulic and $p$-coumaric acids in wheat, corn, rye, and triticale. J. Agr. Food Chem., 37(3), 662-667.

Urbano, G., López-Jurado, M., Aranda, P., Vidal-Valverde, C., Tenorio, E. \& Porres, J. (2000): The role of phytic acid in legumes: antinutrient or beneficial function? J. Physiol. Biochem., 56(3), 283-294.

Yilmaz, F., Yilmaz Tuncel, N. \& Tuncel, N.B. (2018): Stabilization of immature rice grain using infrared radiation. Food Chem., 253, 269-276.

YiLmAZ, N. \& TunCEL, N.B. (2015): The effect of infrared stabilisation on B vitamins, phenolics and antioxidants in rice bran. Int. J. Food Sci. Tech., 50(1), 84-91.

Yilmaz, N., Tuncel, N.B. \& KocabiYIK, H. (2014a): Infrared stabilization of rice bran and its effects on gammaoryzanol content, tocopherols and fatty acid composition. J. Sci. Food Agr., 94(8), 1568-1576.

Yilmaz, N., Tuncel, N.B. \& KocabiYIK, H. (2014b): The effect of infrared stabilized rice bran substitution on nutritional, sensory and textural properties of cracker. Eur. Food Res. Technol., 239(2), 259-265.

Open Access statement. This is an open-access article distributed under the terms of the Creative Commons Attribution-NonCommercial 4.0 International License (https://creativecommons.org/licenses/by-nc/4.0/), which permits unrestricted use, distribution, and reproduction in any medium for non-commercial purposes, provided the original author and source are credited, a link to the CC License is provided, and changes - if any - are indicated. 